\title{
ERRATUM
}

Carsten Schöllner $\cdot$ J. Decking $\cdot$ A. Eckardt

\section{The Artek cup for total hip replacement of dysplastic hip joints}

Published online: 30 July 2003

(C) Springer-Verlag 2003

\section{Arch Orthop Trauma Surg (2003) 123:299-304}

Please note that two coauthors, J. Decking and A. Eckardt, were inadvertently not mentioned in the original publication.

The article was written by C. Schöllner, J. Decking and A. Eckardt.

The online version of the original article can be found at http://dx.doi.org/10.1007/s00402-003-0523-y

C. Schöllner $(\bowtie) \cdot J$. Decking $\cdot$ A. Eckardt

Department of Orthopaedic Surgery,

Johannes Gutenberg University School of Medicine,

Langenbeckstr. 1, 55101 Mainz, Germany

Tel.: +49-6131-172748, Fax: +49-6131-176679,

e-mail: schoelln@mail.uni-mainz.de 